\title{
The Persistence of the Performance in Stock Recommendations of Superior Sell-Side Analysts
}

\author{
Yan-li Geng \\ Shandong Institute of Business and Technology
}

\begin{abstract}
The paper tests the performance of the superior analysts of the new fortune using the event study. The results show that the superior analysts perform better than the ordinary analysts generally and the difference between them is significant. But it is not that all of the superior analysts perform better than the ordinary analysts, the difference between the superior analysts who perform best and the superior analysts who perform worst is significant. And we find that the analysts express some continuity, the superior analysts who performed well in the past also perform well in the future. Our results show that it is not that all of the superior analysts of the new fortune are valuable for following and the investors would not blindly follow the superior analysts.
\end{abstract}

Index Terms - The Superior Analysts; The Profitability; The Persistence

\section{Introduction}

The Wall Street Journal and Chicago tied Alex Investment Research co-sponsored The selection of the nation's best analysts. Every year the superior analysts received applauds, following the increasing of the wages and the reputation. The gap between the superior analysts and the common analysts is significant. Since 2003, The new fortune begin to select the superior analysts in China. Every year there will be 76 best analysts from 26 industry be selected by the new fortune. The superior analysts be selected are also be honored by the market and the investors.

Not only at home or abroad the superior analysts received much more money and reputation than the normal analysts, but there will be an important question that are the superior analysts perform better than the normal analysts? If the investors cann't receive more earnings by following the superior analysts, the superior analysts will not be the true best analysts. Many researchers studied this question in American but there is little study about this question in China, so this article attempt to answer this question.

In this paper I examine the performance of the so-called "sell-side" financial analysts who work for a brokerage house and provide research for the house and its clients. These analysts are prominent in the investment process; indeed, the financial press has called the decade of the 1990s the "Age of the Analysts". While analysts have traditionally influenced institutional investors, they have increasingly influenced individual investors as well.

I measure analyst performance using risk-adjusted returns on portfolios created with analyst recommendations.

Performance persistence, or persistence in the relative performance differences among individual analysts, is measured by the correlation between the differences in individual analyst performance in the estimation period to the one-period-ahead holdout sample. I find significant persistence in relative performance differences among individual analysts. Specifically, analysts whose recommended portfolios generate stronger abnormal returns in the estimation period continue to produce recommended portfolios with stronger abnormal returns in the subsequent holdout periods. The annualized risk-adjusted returns of trading strategies based on performance persistence are statistically and economically significant, with a magnitude around $10 \%$ even after adjusting for transaction costs and trading delays.

The empirical study display that the superior analysts can not perform better than the normal analysts. The performance of the superior analysts will not receive more earnings than the normal analysts. The superior analysts selected by the new fortune performed no better than the normal analysts not only in the year that he/she be selected but also in the year after he/she be selected be the best analysts by the new fortune.

\section{Literature Review}

My paper is related to the literature that examines differential analyst performance and subsequently explains this difference. Richards(1976),Brown and Rozeff(1980), Coggin and Hunter(1989),O'Brien(1990), Butler and Lang, Sinha et al.(1997), and Cooper et al. investigate differences in the performance between the superior analysts and the common analysts. Sinha et al.(1997) is the closest in spirit to my paper. They find that superior earnings forecasters in one period tend to be superior in subsequent holdout periods, which suggests persistence in earnings forecast accuracy.

My paper is also related to the ongoing debate concerning the efficiency with which the market incorporates the information in research reports(Kothari,2001;Lee,2001).For earnings forecast revisions, early research by Griffin(1976), Givoly and Lakonishok(1979,1980), and Imhoff and Lobo(1984) documents abnormal event-period returns. Subsequent research demonstrates an incomplete return reaction during the event period(Givoly and Lakonishok,1980) (Stickel,1991).For stock recommendations, early studies focus on the aggregate performance of a recommendation or recommendation revision category. For example, Elton et al.(1986), Stickel(1995), and Womack show that positive abnormal returns Accompany favorable changes in recommendations with a post-event return drift of up to six months.

Compared to prior research on earnings forecasts, I examine stock recommendations that provide independent information about share value. Compared to prior research on 
recommendations, I employ analyst-level analysis. First, the value of a sell-side research department is its analysts, and thus focusing on performance differences at the analyst level is likely to yield a more profitable trading trategy. Second, while it is impossible even for institutional investors to hold portfolios of the stocks recommended by all analysts or by analysts from a single brokerage house, any investor can trade on the recommended portfolios of individual analysts.

Since many buy-side fund managers rely on research from sell-side analysts, it is interesting to compare the performance persistence of sell-side analysts with that of buy-side fund managers. The evidence on fund managers is mixed. For example, Brown and Goetzmann(1995)find evidence of performance persistence in mutual funds. A recent study by Bollen and Busse(2005)finds performance persistence for mutual funds even after adjusting for momentum, but the persistence is only for quarterly or shorter intervals and the average quarterly abnormal return for the top $10 \%$ of fund managers is about $1.8 \%$.

My most important contribution is to provide clear evidence of a violation of the semi-strion form of the efficient markets hypothesis. The statistically significant abnormal returns found in extant research are eliminated by transaction costs and trading delays and do not constitute violations, In contrast, I document abnormal returns that are many times greater than those reported in prior studies of analysts and fund managers. Even after adjusting for transaction costs and trading delays, these returns are statistically significant and economically meaningful.

\section{Samples and Methodology}

\section{A. Data Sources and Sample Description}

Accounting and return data come from GTA. Stock recommendations are from the RESSET source. The database uses a standardized five-level rating scale, with numeric ratings from 1 through 5 that correspond to "strong buy", "buy", "hold", "under-perform", and "sell" respectively. The recommendation dates are those given in the analyst research reports.

The GTA database has several advantages. First, it is virtually free of survivor bias because recommendations are kept in the database even if an analyst makes no subsequent recommendations. Second, it includes large brokerage houses. Third, in most cases, the extensive brokerage house coverage allows one to track analysts who switch houses. Fourth, recommendation revision dates are included, which allows for changes in analyst portfolios when they occur and if preferable to the use of fixed holding periods such as six or 12 months, which can potentially misrepresent performance.

Table 1 reports characteristics of the average analyst in the standard sample of 5,466 analysts and the characteristics of an average firm in the standard sample of 412 firms. In Panel A, No. Of firms is the number of firms the average analyst covers, No. Of recommendations is the number of analysts at the house that hires the average analyst in the GTA database. If analysts switch houses within a year, they are assigned the average size of the two brokerage houses.
Experience measures the number of years the average number of analysts covering the same firm as the average analyst. To obtain this statistic, I first compute the number of analysts covering the same firm as the average analyst. To obtain this statistic, I first compute the number of analysts covering individual firms. Then I calculate the average across the firms covered by individual analysts. The number for the average analyst is then reported. Panel B reports the mean deciles of the market capitalization, Book-to-Market, Momentum, Share Turnover, and Earnings-to-Price Ratio of the sample firms. Although the results for the medians are not reported in the table, they are very similar to those of means. The average analyst works for a brokerage house employing about 47 analysts and has roughly six years of experience.

The average characteristics of he firms covered by analysts are reported in Panel B of Table 1.Because the actual characteristics are not very informative, I report the average characteristic decile of the sample firms. The deciles are based on NYSE cutoffs. Panel B shows that the firms covered by analysts are larger and have lower book-to-market, greater momentum, higher share turnover, and lower earnings-to-price ratio than the average firm.

Table 1 Analyst and firm charcateristics

\begin{tabular}{ll}
\hline Panel A. Characteristics of an average analyst & \\
No. Of Firms & 15.13 \\
No. Of Recommendations & 13.31 \\
Brokerage House Size & 46.73 \\
Experience & 6.19 \\
Percentage of WSJ Stars & $8.55 \%$ \\
Coverage & 8.48 \\
Panel B. Mean characteristic deciles of sample & \\
Size & 3.66 \\
Book-to-Market & 6.31 \\
Momentum & 5.29 \\
Share Turnover & 4.31 \\
Earnings-to-Price Ratio & 6.06
\end{tabular}

\section{B. Methodology}

I follow Daniel et al.(1997),where I augment the Carhart model with a share turnover factor and an earnings-to-price factor. For each analyst, I first create an equal-weighted buy portfolio based on strong buys, and an equal-weighted sell portfolio based on under-performs and sells. On the date a recommendation is made, the analyst's portfolio is rebalanced to include the recommended stock. The portfolio is again rebalanced to include the recommended stock. The portfolio is again rebalanced to remove the stock on the date the recommendation is revised. This type of calendar-time portfolio directly reflects the experience of a hypothetical investor. I then create 64 passive portfolios based on a $4 * 4 * 4$ design of the quartiles for three factors, namely, size, book-to market, and momentum. To create the CS measure at a daily frequency to match each analyst portfolio, I match each stock in an analyst's buy or sell portfolio with one of the 64 passive portfolios according to its size, book-to-market, and monentum rank. Finally, I use the zero-cost portfolio returns, 
or the daily CS measure defined above, as the dependent variables in a six-factor model to estimate analyst performance within a quarter, a semiannual period, or a year.

\section{Empirical Results}

Analysts are grouped by their performance in an estimation period that is a quarter year, half year, or full year in length. The resulting performance measure is then compared with their performance in a one-period-ahead holdout sample. For example, I construct 27 quarterly estimation samples from the first quarter of 2000 through he third quarter of 2012,with 27 quarterly holdout samples from the second quarter of 2000 through the fourth quarter of 2012.

In the performance persistence test, I regress the subsequent holdout-period performance on the preceding estimation-period performance. The other three tests include several frequently used non-parametric contingency table tests, specifically. To further address the concern about crosssectional correlation, I employ four different regression approaches following Gleason and Lee(2003).The first approach uses analyst-level regressions and the other three approaches use recommendation-level regressions. The first approach is the regression of the a for individual analyst portfolios in the current period on the a in the prior period with the non-overlapping sample used in Table 2.

Table 2 Performance persistence controlling for analyst and firm characteristics-Buy recommendations

\begin{tabular}{lccc}
\hline & \multicolumn{3}{c}{ Buy recommendations } \\
Variable & $(1)$ & $(2)$ & $(3)$ \\
Performance & $0.049 * * *$ & $0.027 * * *$ & $0.019 * *$ \\
II Stars & -0.014 & 0.037 & $0.049 * * *$ \\
WSJ Stars & -0.010 & -0.015 & 0.003 \\
Brokerage Size & $0.001 * * *$ & 0.001 & 0.001 \\
Experience & -0.002 & $-0.005 *$ & -0.003 \\
No. Of Res. & -0.001 & $-0.001 * * *$ & $-0.001 * * *$ \\
Coverage & 0.001 & 0.001 & 0.001 \\
Firm Size & $0.004 * * *$ & $0.014 * * *$ & $0.009 * * *$ \\
Intercept & -0.001 & -0.001 & $-0.003 * * *$ \\
Adjusted $\mathrm{R}^{2}$ & 0.75 & 0.23 & 0.16 \\
\hline
\end{tabular}

Table 3 Performance persistence controlling for analyst and firm characteristics-Sell recommendations

\begin{tabular}{lccc}
\hline & & Sell recommendations & $(3)$ \\
Variable & $(1)$ & $(2)$ & $0.029 * * *$ \\
Performance & $0.083^{* *}$ & 0.014 & $-0.066^{*}$ \\
II Stars & -0.007 & $-0.105^{*}$ & 0.044 \\
WSJ Stars & -0.017 & 0.025 & 0.001 \\
Brokerage Size & -0.001 & 0.001 & $-0.007 * * *$ \\
Experience & 0.003 & $-0.007 * *$ & 0.001 \\
No. Of Res. & 0.001 & 0.001 & 0.001 \\
Coverage & 0.001 & 0.001 & 0.002 \\
Firm Size & -0.001 & 0.003 & $0.142 * * *$ \\
Intercept & -0.008 & $0.076^{* *}$ & 1.95 \\
Adjusted $\mathrm{R}^{2}$ & 1.02 & 0.28 & \\
\hline
\end{tabular}

Table 2 and Table 3 presents the results of the regressions. The results indicate that prior year is almost always significant at the $1 \%$ level for buy recommendations. It is not statistically significant for the second and third approaches for sell recommendations. Overall, performance persistence for buy recommedations is consistently significant at conventional levels even after controlling for cross-sectional correlation and various analyst and firm characteristics. The results suggest that performance persistence is attributable to individual analysts, which is consistent with the finding that analyst aptitude is an important determinant of forecast accuracy.

For sell recommendations, the decline of abnormal returns on decile portfolios with portfolio rank is not as monotonic. For example, the $10^{\text {th }}$ decile portfolios do not have the highest risk-adjusted returns in any case, and risk-adjusted returns are rarely statistically significant at conventional levels. These results are consistent with the finding in Table 3 that performance persistence is weaker for sell recommendations. Interestingly, test statistics for the difference portfolio suggest that persistence is dignificant at annual and semiannual interval, which seems to be mainly due to the negative returns on the $1^{\text {st }}$ decile portfolios.

The magnitude of abnormal returns is unlikely to be explained by alternative estimates of transaction cost, especially considering analysts cover relatively larger stocks. The sizable abnormal returns on the $10^{\text {th }}$ decile portfolio also sharply contrast the results of the extant literature on analysts and fund managers the find small or no trading profits. Moreover, the much higher profits than those in Bollen and Busse(2005)are unlikely to be explained by differences in analysts' and funds' working environments or available data, as I adjust for transaction costs, and following the buy portfolios do not use short selling, which is generally prohibited for fund managers. The magnitude of the difference also cannot be explained by a small percentage of capital held in short-term securities, as required for open-ended fund.

My tests document significant performance persistence, even with various risk adjustments and after controlling for idiosyncratic risk. It is interesting that the amount of persistence decreases as more risk controls are included. For example, using only three-factor matching, performance persistence and trading profitability are far greater. The main risk adjustment I use ,the six-factor model combined with three-factor matching, shows the smallest amount of persistence. This conclusion is consistent both with Brown and Goetxmann'a(1995) proposal that persistence occurs because market participants follow a common strategy not captured by risk adjustment procedures, and with Carhart's(1997) finding that, after controlling for momentum, the performance persistence of mutual funds disappears.

\section{Conclusions}

I examine the persistence in the relative performance of stock recommendations made by individual analysts and find significant evidence of a violation of the semi-strong form of the efficient markets hypothesis. Analysts with above-midian 
risk-adjusted performance in the estimation period consistently outperform those with below-midian performance in the subsequent holdout periods, even with alternative adjustments for cross-sectional correlation, risk, testing methodologies, portfolio weighting schemes, sample period selection, return measurement intervals, and various analyst and firm characteristics. The annualized risk-adjusted returns of trading strategies based on performance persistence are statistically and economically significant, with a magnitude around $10 \%$ even after adjusting for transaction costs and trading delays. This magnitude is many times greater than what is typically found in the existing literature on analysts and fund managers.

The overall persistence stems mostly from past winners and is not a decomposition of post-event return drift as documented by the prior literature. A significant portion of the abnormal returns following analyst recommendations are realized around subsequent announcements of earnings, stock recommendations, and earnings forecasts, especially for the $10^{\text {th }}$ decile analysts, further supporting a market inefficiency explanation. In addition, these abnormal returns that are much greater than those for fund managers do not seem to be due to differences in working environments or data availability between analysts and mutual fund managers, which point to an interesting research question given many fund managers use analyst research. Analyst buy recommendations exhibit much more consistent performance persistence than sell recommendations, In summary, the evidence is consistent with the hypotheses that past winners' recommendations are not more informative, and investors under-react to past winners' recommendations and over-react to past loser' recommendations.

\section{References}

[1] Brown S. J., 1969, "Performance Persistence," The Journal of Finance, 50(2), pp. $679-698$.

[2] Brown L. D. and D. M. Chen, 1991, "How Good is the All-America Research Team in Forecast Earning," Journal of Business Forecasting, 9, pp. 14-18.

[3] Carhart M. M., 1997, "On Persistence in Mutual Fund Performance," The Journal of Finance, 52 (1), pp.57-82.

[4] Desai H. , B. Liang and A. K. Singh, 2000, "Do All-Stars Shine? Evaluation of Analyst Recommendations" Financial Analysts Journal, 56(3),pp.20-29.

[5] Daniel K., M. Grinblatt, S. Titman and R. Wermers, 1997, "Measuring Mutual Fund Performance with Characteristic-Based Benchmarks" The Journal of Finance52(3), pp.1035-1058.

[6] Ertimur Y., J. Sunder and S. V. Sunder,2007, "Measure for Measure: The Relation between Forecast Accuracy and Recommendation Profitability of Analysts" Journal of Accounting Research, 45(3), pp.567-606.

[7] Francis J. and L. Soffer,1997,"The Relative Informativeness of Analysts' Stock Recommendations and Earnings Forecast Revisions" Journal of Accounting Research, 35(2), pp.193-211.

[8] Gleason C. A. and C. M. C. Lee,2003, "Analyst Forecast Revisions and Market Price Discovery” The Accounting Review,78(1), pp.193-225.

[9] Hendricks D. , J. Patel and R. Zeckhauser,1993, "Hot Hands in Mutual Funds: Short-Run Persistence of Relative Performance" The Journal of Finance,48(1), pp.93-130

[10]Lakonishok J. , A. Shleifer and R. W. Vishny, 1992,"The Structure and Performance in the Money Management Industry" Brookings Papers: Microeconomics.

[11]Mikhail M. B. , B. R. Walther and R. H. Willis,2004, "Do Security Analysts Exhibit Persistent Differences" Journal of Financial Economics, 74, pp. 67-91.

[12]Stickel S. E.,1992, "Reputation and Performance Among Security Analysts" The Journal of Finance, 47(5) , pp. 1811-1836. 